\begin{tabular}{ll|l} 
Case Reports in & \multicolumn{2}{c}{ Case Rep Gastroenterol 2017;11:250-255 } \\
\cline { 2 - 3 } Gastroenterology & $\begin{array}{l}\text { DOI: } 10.1159 / 000468512 \\
\text { Publisned onIIne: AprII Z8, 2017 The Author(s) } \\
\text { Published by S. Karger AG, Basel } \\
\text { www.karger.com/crg }\end{array}$ \\
\cline { 2 - 3 } & $\begin{array}{l}\text { This article is licensed under the Creative Commons Attribution-NonCommercial } 4.0 \\
\text { International License (CC BY-NC) (http://www.karger.com/Services/OpenAccessLicense). } \\
\text { Usage and distribution for commercial purposes requires written permission. }\end{array}$
\end{tabular}

\title{
An Uncommon Cause of Small Bowel Bleeding from Appendiceal Carcinoma
}

\author{
Teeranut Boonpipattanapong $^{a} \quad$ Siriboon Attasaranya ${ }^{b} \quad$ Kanita Kayasut $^{c}$ \\ Surasak Sangkhathat ${ }^{a}$ Bancha Ovartlarnporn ${ }^{b}$ \\ a Department of Surgery, Faculty of Medicine, Prince of Songkla University, Hat Yai, \\ Songkhla, Thailand; ${ }^{b}$ NKC Institute of Gastroenterology and Hepatology, Faculty of \\ Medicine, Prince of Songkla University, Hat Yai, Songkhla, Thailand; ' ${ }^{\mathrm{C}}$ Anatomical \\ Pathology Unit, Department of Pathology, Faculty of Medicine, Prince of Songkla \\ University, Hat Yai, Songkhla, Thailand
}

\section{Keywords}

Massive hematochezia $\cdot$ Small bowel bleeding $\cdot$ Mid-gastrointestinal bleeding $\cdot$ Appendiceal carcinoma - Nonmucinous appendiceal adenocarcinoma - Video capsule endoscopy · Enteroscopy $\cdot$ Single-balloon endoscopy

\begin{abstract}
Massive hematochezia caused by a small bowel lesion is a rare entity. Currently, video capsule endoscopy and balloon-assisted enteroscopy are effective in identifying the source of small intestine bleeding. Herein, we report a case of small bowel bleeding caused by a nonmucinous appendiceal adenocarcinoma with ileal invasion which was detected by video capsule endoscopy and single-balloon endoscopy. Despite the advanced disease stage with hepatic and peritoneal metastases, as of September 2016 the patient has had 8 years' disease-free survival after surgical resection and chemotherapy.

(C) 2017 The Author(s) Published by S. Karger AG, Basel
\end{abstract}




\section{Introduction}

Lesions in the small bowel are found in 3-5\% of all patients presenting with acute lower gastrointestinal (GI) bleeding, including arteriovenous malformations, diverticula, and neoplasia [1]. Back then, the gastroscopy and colonoscopy were the only investigations of hematochezia, so the cause of bleeding was difficult to demonstrate. Recent innovations in diagnostic techniques, such as video capsule endoscopy (VCE) and deep endoscopy are highly effective in recognizing small bowel pathology. Herein, we report the first case, to our knowledge, of recurrent massive small bowel bleeding from appendiceal carcinoma invasion detected by the new technologies.

\section{Case Report}

A 77-year-old woman was referred to our surgical unit in 2008 due to recurrent massive hematochezia for the previous 2 weeks. She had no abdominal pain or abnormal bowel symptoms. A colonoscopy performed elsewhere following the first bleeding episode reported a negative result. She had been treated with antihypertensive and antilipidemic agents for 20 years, but had never used any antiplatelets nor NSAIDs. Her only significant medical history was a hemorrhoidectomy 10 years earlier. On admission, she was in a stable condition apart from slight resting tachycardia. No abnormal findings were noted during the physical examination. A complete blood count was unremarkable other than a low hemoglobin level of $8.7 \mathrm{~g} / \mathrm{dL}(12.0-16.0 \mathrm{~g} / \mathrm{dL})$. Rigid sigmoidoscopy revealed a large amount of fresh clotted blood without any mucosal lesion. A gastroscopy revealed a 3-mm erosion in the duodenal bulb without stigmata of bleeding. A colonoscopy then revealed a large amount of fresh blood along the entire colon, mainly in the right-side colon and the terminal ileum without any bleeding source detected. A mesenteric angiography was done following a subsequent active bleeding episode, but found only hyperemia of the vessels at the terminal ileum. A VCE using the Pillcam ${ }^{\mathrm{TM}}$ SB2 (Given Imaging, Yoqneam, Israel) detected a tumor with ulceration in the ileum (Fig. 1). A single-balloon enteroscopy (SBE) (Olympus, Tokyo, Japan) was then performed via the anal route, which confirmed the VCE findings. The provisional diagnosis was GI stromal tumor; however, a biopsy of the tumor was not feasible due to failure to pass the biopsy forceps through the biopsy channel. At laparotomy, a 9-cm tumor at the appendiceal tip adhering to the terminal ileum was found. A small whitish nodule was also detected at the right paracolic gutter and 2 nodules were seen at the omentum. A right hemicolectomy with segmental ileal resection and excision of all 3 nodules was performed.

A surgical specimen revealed that a small ulcer in the ileal mucosa was actually arising from the tumor at the tip of the appendix invading the ileal wall (Fig. 2). The histological examination revealed a poorly differentiated nonmucinous adenocarcinoma (Fig. 3). Metastatic adenocarcinomas were identified in 2 of 16 resected lymph nodes and in all 3 excision nodules. No metastatic foci were found in a chest computerized tomography (CT) scan, but 2 lesions highly suspicious of hepatic metastases were noted in an abdominal CT scan and liver magnetic resonance imaging.

The patient was classified as stage IV (pT4pN1pM1) based on TNM staging of AJCC, 6th edition [2]. She made an uneventful recovery after surgery, and was subsequently treated with 8 cycles of capecitabine. However, a follow-up abdominal CT scan revealed 2 growing hepatic metastases. Thus, the patient was then treated with 6 cycles of a FOLFOX-4 regimen resulting in complete resolution of the liver metastasis by subsequent imaging studies. An 
additional 6 cycles of FOLFOX- 4 were completed. There were no tumor recurrences after 8 years of postoperative follow-up.

\section{Discussion}

Hematochezia from a lesion below the ampulla of Vater to the terminal ileum, defined as mid-GI bleeding [3], is rare. Common causes of small bowel bleeding in patients older than 40 years of age are angiectasia and NSAID enteropathy, while more unusual causes include hemobilia, hemosuccus pancreaticus, aortoenteric fistula [4], Crohn disease, and GIST. In case of recurrent hematochezia, second-look colonoscopy is recommended. However, if this is negative, a VCE should be performed as a first-line procedure for small bowel evaluation [5]. Then, a deep endoscopy with an over-tube-assisted enteroscopy procedure such as SBE, double balloon enteroscopy, or spiral enteroscopy should be considered for lesions identified by VCE to obtain tissue diagnosis and/or guide therapeutic intervention. This intervention should also be considered in cases of persistent bleeding despite a negative VCE or in a case strongly suspicious of small bowel lesion. CT enterography is the alternative investigation if VCE is contraindicated or has a negative result. An emergency angiogram should be performed in active overt bleeding with hemodynamically unstable patients, while CT angiography is recommended in stable patients.

To the best of our knowledge, this is the first report of recurrent massive GI bleeding caused by appendiceal carcinoma invading the terminal ileum. Our patient presented with the single symptom of acute recurrent massive hematochezia with nondiagnostic yield from both upper and lower endoscopies. Mesenteric angiography could not identify a bleeding site. A small bowel study via VCE and SBE revealed an ulcerative tumor at the terminal ileum. An evaluation CT enterography or CT scan might have provided some information in our case but unfortunately we did not do these tests.

Primary appendiceal cancers are quite rare, with an incidence rate of 0.97 cases per 100,000 population [6] accounting for $0.4-1 \%$ of all GI tract malignancies [7]. They are often discovered incidentally from an appendectomy specimen or an intraoperative finding of an unrelated surgery. Overall survival is poor, at least partly due to the usually late disease stage at diagnosis. Primary appendiceal cancers are categorized into epithelial, nonepithelial, and mixed lesions. The epithelial lesions are adenoma and adenocarcinoma [6]. The adenocarcinomas are subdivided into mucinous and nonmucinous adenocarcinomas. Nonmucinous adenocarcinomas account for $27 \%$ of all appendiceal cancers, and $25 \%$ of them have distant metastatic manifestations at diagnosis. The tumor biology, metastatic patterns, and treatment guidelines are similar to colorectal adenocarcinoma. Staging of appendiceal carcinomas followed the 6th edition of AJCC classification for colorectal carcinomas [2]. However, in 2010, the 7th edition of AJCC was released, and appendiceal cancers were classified separately with changed $\mathrm{T}$ and $\mathrm{M}$ categories and stage II and IV diseases further subdivided based on the different treatment and prognosis between mucinous and nonmucinous subtypes [8].

Nonmucinous adenocarcinomas of the appendix generally present with right lower quadrant abdominal pain [9]. The manifestation of massive GI bleeding has never been reported in the nonmucinous type. To the best of our knowledge, our patient is the first case of nonmucinous adenocarcinoma of the appendix causing small bowel bleeding. Murphy and Matar [10] reported 1 case of locally advanced mucinous-type appendiceal adenocarcinoma 
with sigmoid colon and bladder invasion presenting with a small amount of rectal bleeding and hematuria.

A right hemicolectomy with mesocolic lymph node dissection for localized tumors remains the primary treatment that provides a R0 resection and expectable curative outcome [11]. 5-Fluorouracil-based systemic chemotherapy combined with other drugs or biological agents is recommended for advanced diseases. Of note, one study found that patients with a high-grade tumor or a nonmucinous type of appendiceal carcinoma who underwent suboptimal surgery had overall poor prognosis despite postoperative modern systemic chemotherapy [12]. Five-year cancer-specific survival in the poorly differentiated nonmucinous group was only $5 \%$ [13].

As of this writing, although our patient did not receive a hepatic resection and failed the first-line chemotherapy, 2 hepatic metastases dramatically responded to the second-line chemotherapy. She remained recurrence-free after 8 years following the original diagnosis.

In conclusion, this case was interesting due to an unusual presentation of recurrent hematochezia and, despite the generally poor prognosis of advanced nonmucinous appendiceal adenocarcinoma, showed dramatic response to curative resection and additional systemic therapy with long-term disease-free survival.

\section{Acknowledgement}

The authors thank Mr. David Patterson for his assistance in editing the English language of the manuscript.

\section{Statement of Ethics}

The authors have no ethical conflicts to disclose.

\section{Disclosure Statement}

There are no potential conflicts of interest to disclose in association with this study.

\section{References}

1 Vernava AM 3rd, Moore BA, Longo WE, Johnson FE: Lower gastrointestinal bleeding. Dis Colon Rectum 1997;40:846-858.

2 Colon and rectum; in Greene FL, Compton CC, Fritz AG, Shah JP, Winchester DP (eds): AJCC Cancer Staging Atlas, ed 6. New York, Springer, 2006, pp 107-117.

- Ell C, May A: Mid-gastrointestinal bleeding: capsule endoscopy and push-and-pull enteroscopy give rise to a new medical term. Endoscopy 2006;38:73-75.

-4 Raju GS, Gerson L, Das A, Lewis B; American Gastroenterological Association: American Gastroenterological Association (AGA) Institute technical review on obscure gastrointestinal bleeding. Gastroenterology 2007;133:1697-1717.

-5 Gerson LB, Fidler JL, Cave DR, Leighton JA: ACG clinical guideline: diagnosis and management of small bowel bleeding. Am J Gastroenterol 2015;110:1265-1287.

-6 Marmor S, Portschy PR, Tuttle TM, Virnig BA: The rise in appendiceal cancer incidence: 2000-2009. J Gastrointest Surg 2015;19:743-750.

7 Murphy EM, Farquharson SM, Moran BJ: Management of an unexpected appendiceal neoplasm. Br J Surg 2006;93:783-792. 


\section{Gastroenterology}

\begin{tabular}{l|l}
\hline DOI: 10.1159/000468512 & $\begin{array}{l}\text { C } 2017 \text { The Author(s). Published by S. Karger AG, Basel } \\
\text { www.karger.com/crg }\end{array}$ \\
\hline
\end{tabular}

Boonpipattanapong et al:: An Uncommon Cause of Small Bowel Bleeding from Appendiceal Carcinoma

8

Appendix; in Edge SB, Byrd DR, Compton CC, Fritz AG, Greene FL, Trotti A (eds): AJCC Cancer Staging Manual, ed 7. New York, Springer, 2010, pp 133-141.

-9 Hsu JT, Chen HM, Liao CH, Yeh CN, Yeh TS, Hwang TL, Jan YY, Chen MF: Clinicopathologic features and predictors for survival of mucinous and non-mucinous appendiceal adenocarcinoma. Dig Surg 2008;25:369-375.

10 Murphy JA, Matar N: An unusual case of appendiceal adenocarcinoma presenting with rectal bleeding and haematuria. Case Rep Gastroenterol 2009;3:265-268.

11 Ito H, Osteen RT, Bleday R, Zinner MJ, Ashley SW, Whang EE: Appendiceal adenocarcinoma: long-term outcomes after surgical therapy. Dis Colon Rectum 2004;47:474-480.

-12 Tejani MA, ter Veer A, Milne D, Ottesen R, Bekaii-Saab T, Benson AB 3rd, Schrag D, Shibata S, Skibber J, Weiser M, Wilkinson N, Cohen SJ: Systemic therapy for advanced appendiceal adenocarcinoma: an analysis from the NCCN Oncology Outcomes Database for colorectal cancer. J Natl Compr Canc Netw 2014;12:1123-1130.

-13 Overman MJ, Fournier K, Hu CY, Eng C, Taggart M, Royal R, Mansfield P, Chang GJ: Improving the AJCC/TNM staging for adenocarcinomas of the appendix: the prognostic impact of histological grade. Ann Surg 2013;257:1072-1078.

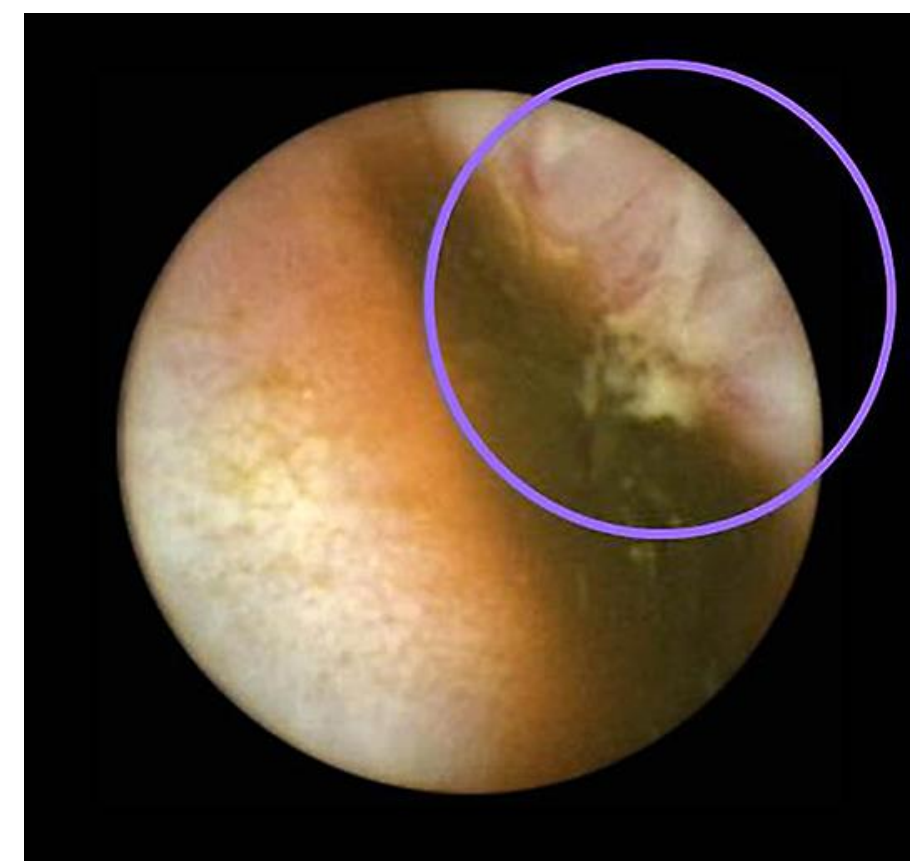

Fig. 1. Video capsule endoscopy showing an ulcerative lesion possibly on the top of the tumor. 


\begin{tabular}{|c|c|c|}
\hline \multirow{3}{*}{$\begin{array}{r}\text { Case Reports in } \\
\text { Gastroenterology }\end{array}$} & \multirow{2}{*}{\multicolumn{2}{|c|}{ Case Rep Gastroenterol 2017;11:250-255 }} \\
\hline & & \\
\hline & DOI: $10.1159 / 000468512$ & $\begin{array}{l}\text { (c) } 2017 \text { The Author(s). Published by S. Karger AG, Basel } \\
\text { www.karger.com/crg }\end{array}$ \\
\hline
\end{tabular}

Boonpipattanapong et al.: An Uncommon Cause of Small Bowel Bleeding from Appendiceal Carcinoma

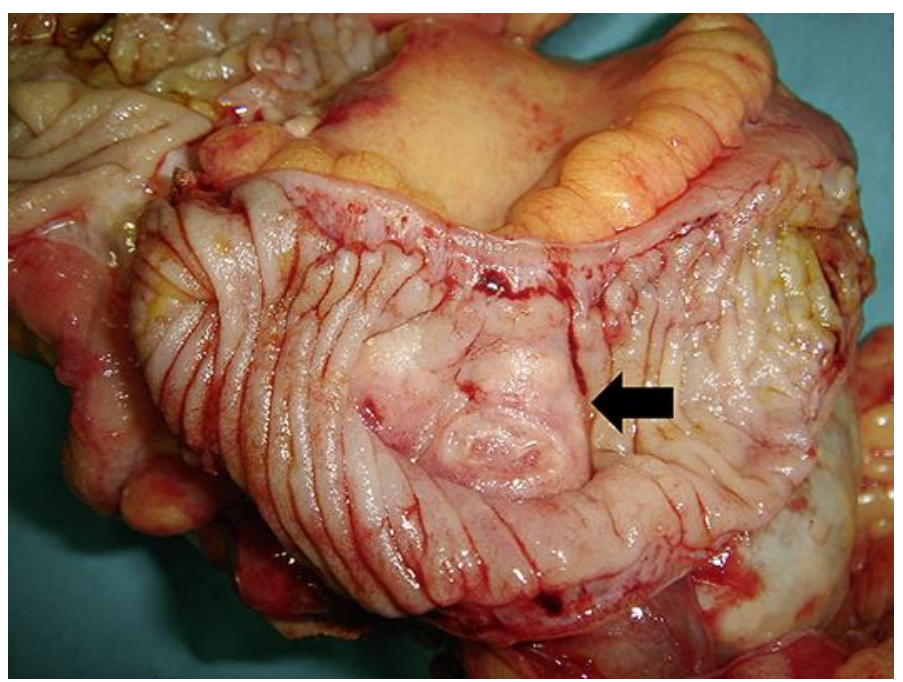

Fig. 2. Open specimen from a right hemicolectomy. The arrow shows an ulcerative mucosal lesion at the terminal ileum as a result of appendiceal tumor invasion.

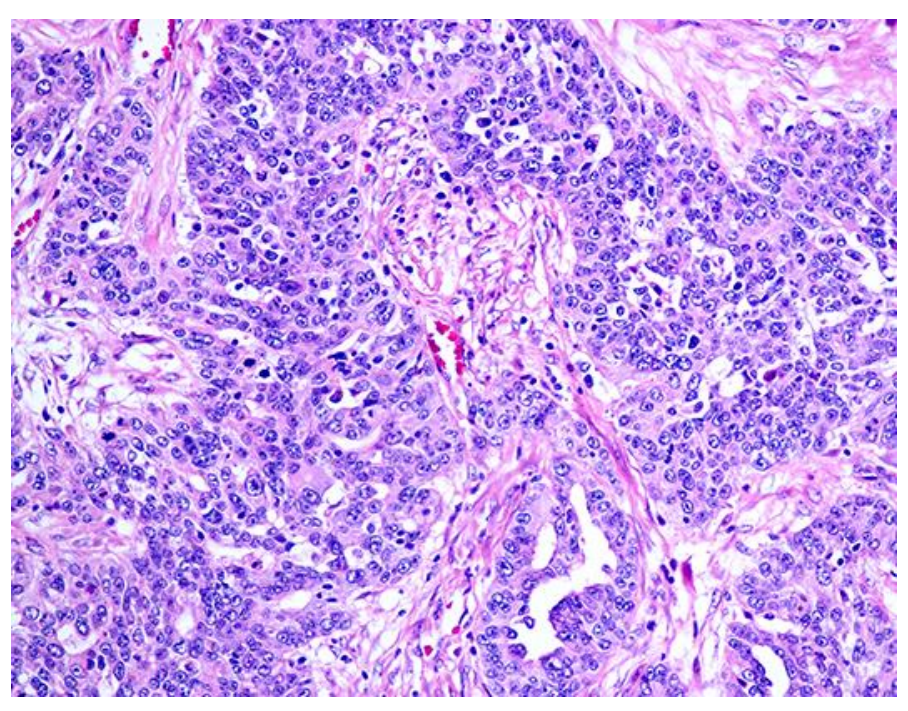

Fig. 3. The pathological diagnosis was nonmucinous poorly differentiated adenocarcinoma. Magnification, $\times 20$. 